\title{
Review
}

\section{Potential protective role of bariatric surgery against breast cancer in postmenopausal women}

\author{
Irina Balescu ${ }^{1}$, Nicolae Bacalbasa ${ }^{2}$ \\ ${ }^{1}$ Ponderas Hospital, Department of General Surgery, Bucharest, Romania \\ ${ }^{2}$ Carol Davila University, Department of General Surgery, Bucharest, Romania
}

\begin{abstract}
Obesity is a major public health problem worldwide especially due to the metabolic disorders which seem to be induced by an excessive amount of adipose tissue. Therefore attention was focused on evaluating the role of bariatric surgery in order to offer a better control of the comorbidities such as diabetes mellitus, arterial hypertension or dyslipidemia which are widely accepted as causes of increased morbidity and mortality among obese patients.

Once these benefits have been widely demonstrated, attention was focused on studying the potential protective role of bariatric surgery against development of various malignancies such a breast, endometrial, pancreatic or even colorectal cancer. This is a literature review regarding the potential protective role of bariatric surgery against breast cancer among obese women worldwide.
\end{abstract}

Keywords: breast cancer, bariatric surgery, obesity, protective role 


\section{Introduction}

Obesity has become a major health problem worldwide, especially due to the associated comorbidities such as dyslipidemia, arterial hypertension, sleep apnea or diabetes mellitus (1-3). Overweight (defined as a body mass index greater than $25 \mathrm{~kg} / \mathrm{m} 2$ ) and obesity (defined as a body mass index greater than $30 \mathrm{~kg} / \mathrm{m} 2$ ) represent common conditions currently, $65 \%$ of the adults in the United States of America being overweight and $30 \%$ of the same population being classified as obese persons (4). All these findings associated with the observation that most patients submitted to conservative, dietary regimens fail to report a consistent, long term weight loss leaded to the apparition of the concept of bariatric surgery. The most common types of surgical bariatric procedures consist of restrictive methods (the most frequently performed being laparoscopic sleeve gastrectomy) or malabsorbtive procedures (such as laparoscopic gastric bypass or duodenal switch). Once the benefits in terms of consistent, permanent weight loss and the amelioration of the associated comorbidities have been widely reported in cases submitted to this kind of surgical approach, bariatric surgery has become the gold standard in treating obese patients (5-7).

Another important pathological correlation was the one between obesity and the development of certain malignancies, most often obese patients being diagnosed with gastrointestinal malignancies (especially colorectal cancer), genitourinary malignancies (such as breast, endometrial, cervical, ovarian, prostatic or kidney carcinomas) and even hematological malignancies (such as lymphomas) (8, 9). Although the first data suggesting this association originates in the early ' 90 's, the first studies demonstrating the strong correlation between obesity and malignant conditions were published in the past few years. These observations, in association with the spectacular improvement of metabolic disorders after bariatric surgery encouraged the surgeons worldwide to study the potential benefits of bariatric surgery in order to provide a protective role against various malignancies.

In the study conducted by Plecka et al. the authors demonstrated that for obesity related cancers (such as breast, prostate, endometrial, kidney or colorectal cancer)the overall incidence ratio is 1,04 for all subjects who were submitted to bariatric surgery compared to general population, demonstrating in this way that bariatric surgery might decrease the malignancy risk in formerly obese patients to a comparable rate with the one reported by normal weight patients (7).

\section{Association between obesity and breast cancer}

In postmenopausal women there is a strong level of evidence that obesity is associated with an increased risk of breast cancer due to an increased level of estrogen (9). In the meantime association of hormone therapy in obese postmenopausal women leads to a higher incidence of breast cancer. Administration of hormone therapy is usually associated with an alteration of hepatic protein synthesis, including an insufficiency of glucose metabolism related proteins (10). Oppositely to postmenopausal women, in premenopausal women things are not so clearly defined: while some studies report an inverse association between obesity and breast cancer risk in premenopausal women (8), or the absence of any kind of correlation (11), other studies consider that obesity might provide a protective role against breast cancer. This phenomenon is explained through the fact that in obese patients severe modifications of the menstrual cycles (leading even to anovulatory infertility) might occur; in consequence a decreased number of ovulations and a reduced estrogen exposure is incriminated (12). 
However, in obese postmenopausal women not only a higher estrogen level leads to a higher incidence of breast cancer. Another important aspect is related to the fact that in this particular situation (obese, postmenopausal woman, with breast malignant tumor) the level of hormone receptors at the tumor level is higher than in normal weight patients. A meta-analysis which was conducted on nine cohorts and 22 casecontrol studies demonstrated that each five unit increase of the medium BMI was associated with a $33 \%$ increased risk of positive estrogen and progesterone receptors (13): this fact increases the sensibility of the tumoral cells to the circulant hormones (which are also present in a higher amount due to the presence of a higher amount of aromatase originating in the adipose tissue) (9). The main mechanisms of action of estrogens which were incriminated for the carcinogenic role consists of an antiapoptotic action of the estrogens in breast tissue in association with the mutagenic effect of the estrogen metabolites. Other hormones which might influence the tumor growth are the androgens; the androgens are also found in a higher amount in obese women and can be easily transformed in estrogens under the action of aromatase (14).

Another important modulator of the mitogenic activity of the cells is insulin. It is well known the fact that obese patients usually have a higher level of plasmatic glucose in association with a higher level of insulin due to the development of insulin resistance. In the meantime, a higher level of plasmatic insulin is associated with a higher mitotic and antiapoptotic effect which comes to accelerate the tissular growth, stimulating the tumoral development (15). The positive correlation between the higher levels of circulating insulin and breast cancer has been also demonstrated by the fact that administration of oral antidiabetic drugs such as metformin is associated with a lower risk of breast cancer. Metformin is a substance which inhibits liver gluconeogenesis leading to a better control of the plasmatic levels of circulating glucose, and, in the meantime, decreasing the insulin resistance. Consequently, the insulin plasmatic levels will decrease and so will happen with its' antiapoptotic effect. Another important mechanism that leads to a lower risk of carcinogenesis in diabetic patients is by modulating the protein kinase activity especially in mTOR cancer-related pathway $(9,16)$.

Other incriminated substances in tumoral development in obese patients are adipokines such as leptin and adiponectin; it has been demonstrated that in obese patients a higher level of leptin can be encountered, which has been also proved to have a mitogenic and antiapoptotic role. In the meantime, a lower level of adiponectin (an adipokine with antimitotic properties) is also usually seen. However the specific influence of adiponectin and leptin on breast cancer development has not been widely recognized, conflicting results being reported so far (17-19).

The role of bariatric surgery in decreasing the breast cancer risk in postmenopausal women

Once the correlation between obesity and breast cancer in postmenopausal women has been widely accepted, the attention was focused on the possible benefits of bariatric surgery on this special situation. The effect of bariatric procedures on the main mechanisms which are supposed to be responsible for this correlation (decreasing the amount of adipose tissue, decreasing the insulin resistance and modifying the levels of adipokines) transformed this surgical approach in a successful weapon in order to prevent the apparition of breast cancer in obese postmenopausal women.

The retrospective study conducted by McCawley et al. included 1482 patients submitted to bariatric surgery; among these cases 53 patients were also diagnosed with associate malignancies, breast and endometrial cancers representing the most frequently encountered cancers (in 15 and 9 patients respectively). Thirty four patients were diagnosed and treated for their malignancies before performing a 
bariatric procedure, the mean interval between cancer diagnosis and bariatric surgery being of 9,9 years. Other 17 patients were diagnosed with a malignant tumor after bariatric surgery, the mean interval being of 4,2 years. One patient was diagnosed during the preoperative workup while in another case the moment of cancer diagnosis remained unknown. Breast cancer was diagnosed during the preoperative workup for bariatric surgery in $46,7 \%$ of cases and after bariatric surgery in $53,3 \%$ of cases. These patients had a mean age of 46 years at the moment of breast cancer diagnosis and a mean BMI of $50,8 \mathrm{~kg} / \mathrm{m}^{2}$. The results were compared to the ones reported in a control group constituted by obese patients who were not submitted to bariatric surgery. Among these patient breast cancer was diagnosed in $9,4 \%$ of cases, while the mean age at diagnosis of breast cancer was 57,3 years. The authors demonstrated that bariatric surgery decreased breast cancer development in these patients; however it was not well established if the lower rates of breast cancer after performing a bariatric procedure were related to the metabolic changes induced by weight loss or if decreasing the patients' BMI leaded to an earlier diagnosis of a potential breast tumor (20).

In one of the most popular studies regarding the benefits of bariatric surgery the authors included 2010 patients submitted to bariatric procedures after 1987 and the results were compared with 20137 matched controls. After a median follow up of 10,9 years the hazard ratio of malignancy development in women who had been submitted to bariatric surgery was 0,58 as compared with those who were treated in a conservative manner. Similarly to McCawley's study, breast cancer and endometrial cancer were the most frequently encountered (in 23\% and 22\% of cases respectively) but data did not suggest a significant benefit for each type of malignancy individually (21).

Adams et al. demonstrated that the hazard ratio of developing any malignancy in obese women after a mean follow up of 12,5 years (after performing a bariatric procedure) was 0,73 (95\% confidence interval $0,62-0,87$ ); however the data regarding breast cancer was not significant (22).

Other studies demonstrate an even closer connection between bariatric surgery and risk reduction of breast cancer; bariatric surgery proved to lower the risk of breast cancer development by $80 \%$ during the 5 years postoperatively (23).

\section{Conclusions}

Although the protective role of bariatric surgery against breast cancer development in obese postmenopausal women is not well defined yet, a decrease of the incidence has been suggested in the studies conducted so far. The main incriminated mechanisms are related to the modulation of estrogen, insulin and adipokines' synthesis. However, large studies are still needed to offer a better analysis of this subject.

\section{References}

1. Martinez CA, Walters JA 3rd, Sato EA, Hall JJ, Boutros SG. Deep Inferior Epigastric Artery Perforator Flap Breast Reconstruction in Patients With Previous Bariatric Surgery: Is It Safe and Feasible? Ann Plast Surg. 2016; 76(2): 216-20. PMID: 26756599

\section{https://doi.org/10.1097/SAP.0000000000000526}

2. Hedley AA, Ogden CL, Johnson CL, Carroll MD, Curtin LR and Flegal KM: Prevalence of overweight and obesity among US children, adolescents and adults, 1999-2002. JAMA 2004; 291(23): 2847-50. PMID: 15199035

\section{https://doi.org/10.1001/jama.291.23.2847}

3. Calle EE, Rodriguez C, Walker-Thurmond K and Thun MJ: Overweight, obesity and mortality from cancer in a prospectively studied cohort of U.S. adults. $N$ Engl J Med. 2003; 348: 1625-38. PMID: 12711737

https://doi.org/10.1056/NEJMoa021423 
4. Calle EE and Thun MJ: Obesity and cancer. Oncogene 2004; 23(38): 6365-78. PMID: 15322511 https://doi.org/10.1038/sj.onc.1207751

5. Ostlund MP, Lu Y and Lagergren J. Risk of obesity-related cancer after obesity surgery in a population-based cohort study. Ann Surg 2010; 252(6): 972-76. PMID: 20571362

\section{https://doi.org/10.1097/SLA.0b013e3181e33778}

6. Renehan AG, Tyson M, Egger M, Heller RF and Zwahlen M. Body-mass index and incidence of cancer: a systematic review and meta-analysis of prospective observational studies. Lancet 2008; 371: 569-578. PMID: 18280327

\section{https://doi.org/10.1016/S0140-6736(08)60269-X}

7. Petit JY, Maisonneuve P, Rotmensz N, Bertolini F, Clough KB, Sarfati I, Gale KL, Macmillan RD, Rey P, Benyahi D, Rietjens M. Safety of Lipofilling in Patients with Breast Cancer. Clin Plast Surg. 2015; 42(3): 339-44. PMID: 26116939 https://doi.org/10.1016/j.cps.2015.03.004

8. Gunter MJ, Hoover DR, Yu H, WassertheilSmoller S, Rohan TE, Manson JE, Li J, Ho GY, Xue $\mathrm{X}$ anderson GL, Kaplan RC, Harris TG, Howard BV, Wylie-Rosett J, Burk RD, Strickler HD. Insulin, insulin-like growth factor-I and risk of breast cancer in postmenopausal women. $J$ Natl Cancer Inst 2009; 101(1): 48-60. PMID: 19116382 https://doi.org/10.1093/jnci/djn415

9. Avashia YJ, Desrosiers AE 3rd, Flores JI. A second superior gluteal artery perforator flap with previous liposuction to the same breast after resection of initial SGAP breast reconstruction due to cancer recurrence. Microsurgery. 2012; 32(6): 482-4. PMID: 22718270

\section{https://doi.org/10.1002/micr.21989}

10. Winfree LE, Henretta MS, Hallowell PT, Modesitt SC. Pre-operative gynecologic evaluation of bariatric surgery patients: improving cancer detection in a high-risk population. $J$ Am Coll Surg. 2010; 211(2): 256-62. PMID: 20670865 https://doi.org/10.1016/j.jamcollsurg.2010.03.011

11. Suzuki R, Iwasaki $M$, Inoue $M$, Sasazuki S, Sawada N, Yamaji T, Shimazu T and Tsugane S: Body weight at age 20 years, subsequent weight change and breast cancer risk defined by estrogen and progesterone receptor status--the Japan public health center-based prospective study. Int $J$ Cancer 2011; 129(5): 1214-24. PMID: 21064092 https://doi.org/10.1002/ijc.25744

12. Zhang $\mathrm{X}$, Tworoger SS, Eliassen $\mathrm{AH}$ and Hankinson SE. Postmenopausal plasma sex hormone levels and breast cancer risk over 20 years of follow-up. Breast Cancer Res Treat 2013; 137(3): 883-92. PMID: 23283524

\section{https://doi.org/10.1007/s10549-012-2391-Z}

13. Gusenoff JA, Koltz PF, O'Malley WJ, Messing S, Chen R, Langstein HN. Breast cancer and bariatric surgery: temporal relationships of diagnosis, treatment, and reconstruction. Plast Reconstr Surg. 2009; 124(4): 1025-32. PMID: 19935285

https://doi.org/10.1097/PRS.0b013e3181b457ea

14. Goodwin PJ, Stambolic V, Lemieux J, Chen BE, Parulekar WR, Gelmon KA, Hershman DL, Hobday TJ, Ligibel JA, Mayer IA, Pritchard KI, Whelan TJ, Rastogi $\mathrm{P}$ and Shepherd LE: Evaluation of metformin in early breast cancer: a modification of the traditional paradigm for clinical testing of anti-cancer agents. Breast Cancer Res Treat. 2011; 126(1): 215-20. PMID: 20976543 https://doi.org/10.1007/s10549-010$\underline{1224-1}$

15. Jarde T, Perrier S, Vasson MP and CaldefieChezet F. Molecular mechanisms of leptin and adiponectin in breast cancer. Eur J Cancer 2011; 47(1): 33-43. PMID: 20889333

https://doi.org/10.1016/j.ejca.2010.09.005 
16. Gaudet MM, Falk RT, Gierach GL, Lacey JV, Jr., Graubard BI, Dorgan JF and Brinton LA. Do adipokines underlie the association between known risk factors and breast cancer among a cohort of United States women? Cancer Epidemiol. 2010; 34(5): 580-6. PMID: 20579950 https://doi.org/10.1016/j.canep.2010.05.014

17. Falco J, Dip F, Quadri P, de la Fuente M, Rosenthal R. Cutting Edge in Thyroid Surgery: Autofluorescence of Parathyroid Glands. J Am Coll Surg. 2016; 223(2): 374-80. PMID: 27212004 https://doi.org/10.1016/j.jamcollsurg.2016.04.049

18. McCawley GM, Ferriss JS, Geffel D, Northup CJ and Modesitt SC: Cancer in obese women: potential protective impact of bariatric surgery. $J$ Am Coll Surg 2009; 208(6): 1093-8. PMID: 19476897

https://doi.org/10.1016/j.jamcollsurg.2009.01.045

19. Sjostrom L, Gummesson A, Sjostrom CD, Narbro K, Peltonen M, Wedel H, Bengtsson C, Bouchard C, Carlsson B, Dahlgren S, Jacobson P, Karason K, Karlsson J, Larsson B, Lindroos AK, Lonroth H, Naslund I, Olbers T, Stenlof K, Torgerson J and Carlsson LM. Effects of bariatric surgery on cancer incidence in obese patients in Sweden (Swedish Obese Subjects Study): a prospective, controlled intervention trial. Lancet Oncol 2009; 10(7): 653-62. PMID: 19556163

\section{https://doi.org/10.1016/S1470-2045(09)70159-7}

20. Noun R, Slim R, Nasr M, Chakhtoura G, Gharios J, Antoun NA, Ayoub E. Results of Laparoscopic Sleeve Gastrectomy in 541 Consecutive Patients with Low Baseline Body Mass Index (30-35 kg/m2). Obes Surg. 2016; 26(12): 2824-2828. PMID: 27185176 https://doi.org/10.1007/s11695$\underline{016-2224-y}$

21. Ruiz-Lozano T, Vidal J, de Hollanda A, Scheer FA, Garaulet M, Izquierdo-Pulido M. Timing of food intake is associated with weight loss evolution in severe obese patients after bariatric surgery. Clin Nutr. 2016; 35(6): 1308-1314. PMID: 26948400

\section{https://doi.org/10.1016/j.clnu.2016.02.007}

22. Masia J, Pons G, Nardulli ML. Combined Surgical Treatment in Breast Cancer-Related Lymphedema. J Reconstr Microsurg. 2016; 32(1): 16-27. PMID: 25868153 https://doi.org/10.1055/s-0035-1544182

23. Merchant SJ, Chen SL. Prevention and management of lymphedema after breast cancer treatment. Breast J. 2015; 21(3): 276-84. PMID: 25772311 https://doi.org/10.1111/tbj.12391 